\title{
Hubungan Peran Manajer dengan Pelaksanaan Pencegahan dan Pengendalian Infeksi Rumah Sakit di Ruang Rawat Inap Bedah RSUP Dr.M.Djamil Padang Tahun 2016
}

\author{
Rozada Alemania ${ }^{1}$, Defriman Djafri ${ }^{2}$, Aumas Pabuti $^{3}$
}

\begin{abstract}
Abstrak
Infeksi Rumah Sakit saat ini merupakan salah satu penyebab meningkatnya angka kesakitan (morbidity) dan angka kematian (mortality) di rumah sakit. Kepala ruangan sebagai manajer harus terus membina stafnya agar program pengendalian infeksi berjalan sesuai kesepakatan. Tujuan penelitian ini adalah mengetahui hubungan peran manajer dengan pelaksanaan pencegahan dan pengendalian infeksi rumah sakit di ruang rawat inap bedah RSUP Dr.M.Djamil Padang tahun 2016. Penelitian ini bersifat deskriptif menggunakan metode kombinasi (Mix Methode). Pengambilan data dilakukan melalui kuesioner, wawancara, observasi dan telaah dokumen. Analisis data dilakukan secara univariat, bivariat dan analisis isi. Tekhnik pengambilan sampel secara Proportionate stratified random sampling. Teknik penentuan informan dengan menggunakan purposive sampling. Hasil penelitian kuantitatif menunjukkan tidak ada hubungan antara peran interpersonal dengan pelaksanaan pencegahan dan pengendalian infeksi RS ( $p=0,117)$, ada hubungan antara peran informasional $(p=0,003)$, peran decisional $(p=0,000)$ dengan pelaksanaan pencegahan dan pengendalian infeksi RS. Hasil penelitian kualitatif menggambarkan peran manajer dan pelaksanaan pencegahan dan pengendalian infeksi RS masih belum optimal di ruang rawat inap bedah RSUP Dr.M.Djamil Padang tahun 2016.
\end{abstract}

Kata kunci: infeksi rumah sakit, peran manajer, ruang rawat inap bedah

\section{Abstract}

Hospital infection is currently one of the increased rates of pain (morbidity rate) and the death (mortality rate) in the hospital. Head of the room or head nurse as manager, must continuously coaching staff to control infection so the hospital control infection's program runs as agreement. The objective of this study was to understand the relationship between the role of manager with the implementation of hospital prevention and control in inpatient rooms surgical RSUP DR.M.Djamil Padang, 2016. This research is descriptive by using the method combination (mix method). The data was undertaken in questionnaire completion, observation, and review of documentation. Analysis of data using univariate, bivariate and contents analysis. Sample taking by Proportionate stratified random sampling, Informants defining used purposive sampling method. Results quantitatively showing no a significant relation exists between the role of interpersonal with the hospital prevention and control infections ( $p$-value $=0,117$ ), a significant relation between informational role $(p$-value $=0,003)$, decisional role $(p$-value $=0,000)$ with the hospital prevention and control infections. Qualitatively show that manager role and implementation of hospital prevention and control infections are not yet optimal in surgical inpatient rooms RSUP Dr.M.Djamil Padang, 2016.

Keywords: hospital infection, manager role, surgical inpatient rooms

Affiliasi penulis: 1. Prodi Pascasarjana S2 Kesehatan Masyarakat Fakultas Kedokteran Universitas Andalas Padang (FK Unand), 2. Bagian IImu Kesehatan Masyarakat FK Unand, 3. Bagian IImu Kesehatan Anak FK Unand/RSUP Dr.M.Djamil Padang
Korespondensi: Rozada Alemania, Email:

alemaniahutasuhut@gmail.com, Hp.081363213924 


\section{PENDAHULUAN}

Infeksi yang berkaitan dengan pelayanan kesehatan yaitu Health Care Associated Infection (HAls), saat ini merupakan salah satu penyebab meningkatnya angka kesakitan (morbidity) dan angka kematian (mortality) di rumah sakit. HAls dapat menjadi masalah kesehatan baru, baik di negara berkembang maupun di negara maju. Rumah Sakit (RS) dituntut untuk dapat memberikan pelayanan yang bermutu sesuai dengan standar yang sudah ditentukan dan harus diterapkan oleh semua kalangan petugas kesehatan. ${ }^{1}$

Hal ini merupakan masalah serius bagi semua sarana pelayanan kesehatan di seluruh dunia, termasuk di Indonesia. Buku pedoman manajerial pencegahan dan pengendalian infeksi rumah sakit dan pelayanan kesehatan lainnya yang di terbitkan oleh Departemen Kesehatan RI tahun 2008 menyebutkan bahwa dari hasil penelitian yang dilakukan National Nosocomial Infections Surveillance (NNIS) dan Centers of Disease Control and Prevention's (CDC's) pada tahun 2002 melaporkan bahwa 5 sampai 6 kasus HAls dari setiap 100 kunjungan ke rumah sakit. Diperkirakan 2 juta kasus HAls terjadi setiap tahun di Amerika Serikat dengan menghabiskan dana 2 milyar dolar. ${ }^{2}$

Di Indonesia sendiri, baru terdapat data HAls dari 10 RSU pendidikan. Didapatkan angka kejadian HAls yang cukup tinggi, berkisar antara 6-16 \% dengan rata-rata 9,8\%. Infeksi yang paling umum terjadi adalah Infeksi Daerah Operasi (IDO). Hasil penelitian lain menunjukkan bahwa angka kejadian IDO pada RS di Indonesia bervariasi antara 2-18\% dari keseluruhan prosedur pembedahan. ${ }^{2}$

Perawat sangat berperan dalam pengendalian infeksi sebab perawat merupakan praktisi kesehatan yang berhubungan langsung dengan klien dan bahan infeksius di ruang rawatan. Keberhasilan kerja para perawat pelaksana sangat bergantung pada upaya manajerial keperawatan. ${ }^{3}$

Manajer keperawatan memiliki posisi tanggung jawab yang kompleks dalam organisasi pelayanan kesehatan. ${ }^{4}$ Dalam melaksanakan perananannya sebagai manajer lini pertama, kepala ruangan menjalankan peranan manajer.
RSUP Dr.M Djamil Padang sebagai rumah sakit pusat rujukan untuk wilayah Sumatera Bagian Tengah. Hal tersebut dapat memberikan gambaran bahwa RSUP Dr.M.Djamil Padang merupakan rumah sakit padat tenaga kesehatan termasuk tenaga kesehatan yang melakukan praktik di RSUP Dr.M.Djamil Padang dan padat hunian. Hal ini memungkinkan terhadap resiko penyebaran infeksi di rumah sakit.

Unit kerja bedah merupakan unit kerja fungsional di rumah sakit yang paling beresiko terjadinya infeksi. Hal ini dapat di mengerti karena unit kerja inilah yang paling banyak melakukan tindakan medis invasive terutama adanya tindakan medis invasive terapeutik. ${ }^{1}$

Kepatuhan petugas dalam pelaksanaan pencegahan dan pengendalian infeksi rumah sakit di ruang rawat inap bedah RSUP Dr.M.Djamil Padang masih jauh dari target yang ditetapkan oleh komite Pencegahan dan Pengendalian Infeksi Rumah Sakit (PPIRS) RSUP Dr.M.Djamil Padang.

Pelaksanaan PPIRS di RSUP Dr.M.Djamil Padang merupakan salah satu poin yang menyebabkan RSUP Dr.M.Djamil Padang remedial dalam upaya mencapai nilai akreditasi paripurna.

Penelitian ini bertujuan untuk mengetahui hubungan peran manajer dengan pelaksanaan pencegahan dan pengendalian infeksi rumah sakit di ruang rawat inap bedah RSUP Dr.M.Djamil Padang tahun 2016.

\section{METODE}

Penelitian deskriptif ini menggunakan metode kombinasi (Mix Methode) model urutan pembuktian (sequential explanatory). Pengambilan data dilakukan dengan penyebaran kuesioner, wawancara, observasi, dan telaah dokumen. Analisis data dilakukan secara univariat, bivariat dan analisis isi. Teknik pengambilan sampel secara Proportionate stratified random sampling. Teknik penentuan informan dengan menggunakan purposive sampling.

Penelitian dilaksanakan di ruang rawat inap bedah RSUP Dr.M.Djamil Padang dari bulan Juni sampai dengan Bulan September 2016. 
HASIL

\section{Hasil Penelitian Kuantitatif}

Sampel pada penelitian kuantitatif berjumlah 48 perawat pelaksana. Rerata umur responden adalah 37,19 tahun (95\% Cl: 35,03-39,35), umur termuda 25 tahun dan umur tertua 56 tahun. Rerata lama bekerja responden adalah 12,04 tahun (95\% Cl: 9,81-14,27), Lama bekerja terendah 1 tahun dan tertinggi 36 tahun.

Jenis kelamin relatif homogen $(93,8 \%$ perempuan), sebagian besar responden $(85,4 \%)$ dengan tingkat pendidikan D3, serta sebagian besar $(87,5 \%)$ responden pernah mengikuti pelatihan yang terkait dengan Pencegahan dan Pengendalian Infeksi RS (PPIRS).

Hubungan antara peran manajer (interpersonal, informasional, decisional) dengan pelaksanaan PPIRS dari hasil pengisian kuesioner oleh 48 orang perawat pelaksana dapat di lihat pada Tabel 1.

Tabel 1. Hubungan peran manajer dengan pelaksanaan PPIRS

\begin{tabular}{|c|c|c|c|c|c|c|c|}
\hline \multirow{3}{*}{$\begin{array}{c}\text { Variabel } \\
\text { Peran }\end{array}$} & \multicolumn{6}{|c|}{$\begin{array}{c}\text { Pelaksanaan Pencegahan dan } \\
\text { Pengendalian Infeksi Rumah Sakit } \\
\text { (PPIRS) }\end{array}$} & \multirow{3}{*}{ p } \\
\hline & \multicolumn{2}{|c|}{ Baik } & \multicolumn{2}{|c|}{$\begin{array}{l}\text { Tidak } \\
\text { Baik }\end{array}$} & \multicolumn{2}{|c|}{ Total } & \\
\hline & $f$ & $\%$ & $f$ & $\%$ & $f$ & $\%$ & \\
\hline \multicolumn{8}{|l|}{$\begin{array}{l}\text { Inter- } \\
\text { personal }\end{array}$} \\
\hline Baik & 12 & 42,9 & 16 & 57,1 & 28 & 100 & 111 \\
\hline Tidak & 14 & 70 & 6 & 30 & 20 & 100 & \\
\hline \multicolumn{8}{|l|}{ Informasi } \\
\hline Baik & 12 & 37,5 & 20 & $0<, 5$ & 32 & 100 & 0,003 \\
\hline Tidak & 14 & 87,5 & 2 & 12,5 & 16 & 100 & \\
\hline \multicolumn{8}{|l|}{ Decision } \\
\hline Baik & 11 & 34,4 & 21 & 65,6 & 32 & 100 & 0,000 \\
\hline Tidak & 15 & 93,8 & 1 & 6,2 & 16 & 100 & \\
\hline
\end{tabular}

Hasil uji Chi-square untuk peran interpersonal diperoleh $p=0,117$. Hal ini menunjukkan tidak ada hubungan antara peran interpersonal dengan pelaksanaan PPIRS
Hasil uji Chi-square untuk peran informasional, diperoleh $p=0,003$. Hal ini menunjukkan ada hubungan antara peran informasional dengan pelaksanaan pencegahan dan pengendalian infeksi RS.

Hasil uji Chi-square untuk peran decisional diperoleh $p=0,000$. Hal ini menunjukkan ada hubungan antara peran decisional dengan pelaksanaan pencegahan dan pengendalian infeksi RS.

\section{Variabel Confounding}

Variabel yang di duga mempengaruhi dalam pelaksanaan PPIRS pada penelitian ini ialah usia, jenis kelamin, tingkat pendidikan, masa bekerja dan pelatihan terkait PPIRS yang pernah di ikuti responden.

Tabel 2. Hubungan rerata umur responden menurut pelaksanaan pencegahan dan pengendalian infeksi rumah sakit (PPIRS)

\begin{tabular}{lll}
\hline Pelaksanaan PPIRS & Rerata & $\mathbf{p}$ \\
\hline Baik & 25,35 & 0,648 \\
Tidak Baik & 23,50 & \\
\hline
\end{tabular}

Hasil uji statistik didapatkan nilai $p=0,648$, berarti tidak ada perbedaan yang signifikan rerata umur responden yang melaksanakan pencegahan dan pengendalian infeksi RS baik dengan kurang baik.

Tabel 3. Hubungan rerata lama bekerja responden menurut pelaksanaan pencegahan dan pengendalian infeksi (PPIRS)

\begin{tabular}{lcc}
\hline \multicolumn{1}{c}{ Pelaksanaan PPIRS } & Rerata & p \\
\hline Baik & 26,60 & \multirow{2}{*}{0,256} \\
Tidak Baik & 22,02 & \\
\hline
\end{tabular}

Hasil uji statistik didapatkan nilai $p=0,256$, berarti tidak ada perbedaan yang signifikan rerata lama bekerja responden yang melaksanakan pencegahan dan pengendalian infeksi RS baik dengan tidak baik. 
Tabel 4. Hubungan jenis kelamin, pendidikan dan pelatihan dengan pelaksanaan pencegahan dan pengendalian infeksi RS (PPIRS)

Pelaksanaan Pencegahan dan

Pengendalian Infeksi Rumah Sakit

Variabel (PPIRS)

\begin{tabular}{|c|c|c|}
\hline Baik & Tidak Baik & Total \\
\hline
\end{tabular}

\begin{tabular}{llllllll}
$\begin{array}{l}\text { Jenis } \\
\text { Kelamin }\end{array}$ & & & & & & & \\
Perempuan & 24 & 53,3 & 21 & 46,7 & 45 & 100 & 1,00 \\
Laki-Laki & 2 & 66,7 & 1 & 33,3 & 3 & 100 & \\
Pendidikan & & & & & & & \\
S2 & 1 & 100 & 0 & 0 & 1 & 100 & \\
S1 & 1 & 16,7 & 5 & 83,3 & 6 & 100 & 0,102 \\
D3 & 24 & 58,5 & 17 & 41,5 & 41 & 100 & \\
Pelatihan & & & & & & & \\
Ya & 22 & 52.4 & 20 & 47.6 & 42 & 100 & 0,674 \\
Tidak & 4 & 66.7 & 2 & 33.3 & 6 & 100 & \\
\hline
\end{tabular}

Tabel diatas menunjukkan hasil uji Chi-square diperoleh $p=1,000$ untuk variabel jenis kelamin, $p=$ 0,102 untuk variabel pendidikan dan $p=0,674$ untuk variabel pelatihan. Jika dibandingkan nilai $p$ masingmasing variabel tersebut dengan nilai koefisien $\geq$ 0,05 , maka $p>0,05$. Hal ini menunjukkan tidak ada hubungan antara jenis kelamin, pendidikan, dan pelatihan dengan pelaksanaan pencegahan dan pengendalian infeksi RS

\section{Hasil Penelitian Kualitatif}

Informan berjumlah 6 orang yaitu Infection Prevention and Control Link Nurse (IPCLN) di ruang rawat inap bedah RSUP Dr.M.Djamil Padang. Rerata umur informan adalah 47,85 tahun dengan usia terendah 43 tahun dan usia tertinggi 53 tahun. Sebagian besar informan berjenis kelamin perempuan $(85,71 \%)$, rerata informan berpendidikan S1. Lama bekerja informan sebagai IPCLN adalah \pm 1 tahun

Seluruh informan IPCLN telah mengikuti pelatihan terkait pencegahan dan pengendalian infeksi RS yang di selenggarakan oleh RS (Komite PPIRS RSUP Dr.M.Djamil Padang).

Observasi yang dilakukan merupakan observasi non partisipan selama 1-2 hari di 6 ruang rawat inap bedah. Pengamatan terhadap pelaksanaan pencegahan dan pengendalian infeksi rumah sakit di lakukan terhadap perawat pelaksana di ruang rawat inap bedah yang berjumlah 13 orang berpendidikan D3 keperawatan, jenis kelamin perempuan. Saat melakukan pengamatan, peneliti juga melakukan wawancara bebas dengan 6 orang pasien atau keluarga pasien di ruang rawat inap bedah.

Peran interpersonal, dari hasil analisis triangulasi setelah dibandingkan dengan hasil kuesioner, wawancara dan observasi di ketahui bahwa IPCLN dalam menjalankan peran interpersonalnya belum optimal dalam memberikan arahan, motivasi pada perawat ruangan untuk melaksanakan pencegahan dan pengendalian infeksi RS dengan baik.

Hasil triangulasi berdasarkan pada analisa kuesioner, wawancara dan observasi terhadap peran informasional IPCLN di ruang rawat inap bedah, di ketahui bahwa IPCLN belum optimal dalam mengumpulkan informasi, menyampaikan informasi mengenai pelaksanaan PPIRS oleh petugas baik ke dalam maupun ke luar organisasi yang di pimpinnya (ruang rawat inap bedah).

Sedangkan hasil analisis triangulasi untuk Peran decisional, peran IPCLN belum berjalan dengan optimal dimana IPCLN tidak memantau pelaksanaan PPIRS berkesinambungan, evaluasi tidak setiap saat di lakukan dan tidak ada pendokumentasian dari evaluasi tersebut.

Pengamatan juga dilakukan terhadap pelaksanaan pencegahan dan pengendalian infeksi rumah sakit oleh perawat. Setelah dibandingkan dengan analisa kuesioner, wawancara dan pengamatan, diketahui bahwa pelaksanaan pencegahan dan pengendalian infeksi RS di ruang rawat inap bedah masih belum sesuai standar dari PPIRS yaitu masih ada petugas yang tidak melakukan Hand Hygiene sebelum melakukan tindakan keperawatan, tidak mengenakan Hand Scoen, tidak segera melepas Hand scoen setelah melakukan tindakan, masih ada petugas yang meletakkan linen kotor di lantai dan mengangkut nya dengan tangan tanpa menggunakan wadah khusus, masih ada limbah yang tidak di letakkan pada wadah yang tepat, masih ada limbah benda tajam yang di buang pada safety box yang telah penuh. 


\section{PEMBAHASAN}

\section{Hubungan Peran Manajer dengan Pelaksanaan PPIRS}

Peran manajer dapat mempengaruhi faktor motivasi dan lingkungan. Peran manajer juga mungkin mempengaruhi faktor lain, bergantung pada tugas manajer, bagaimana manajer bekerja dalam suatu organisasi. ${ }^{5}$

Hasil penelitian Jayatri dan Samian (2010) didapatkan ada hubungan yang signifikan antara peranan manajer dengan kepuasan kerja. Peran tersebut meliputi peran manajer dalam membina hubungan personal yang baik dengan karyawan (peran interpersonal), peran sebagai pengendali informasi baik di dalam maupun di luar organisasi (Peran informasional) dan peran sebagai pengambil keputusan yang terbaik bagi organisasi (peran decisional). ${ }^{6}$

Marliany et al 2010 mendapatkan hasil bahwa peran kepala ruangan secara komposit berhubungan signifikan dengan sikap etis perawat terhadap klien $(p=0,002)^{7}$

Hasil analisis hubungan antara peran interpersonal IPCLN dengan pelaksanaan PPIRS menunjukkan ada hubungan yang signifikan antara peran interpersonal dengan pelaksanaan pencegahan dan pengendalian infeksi $R S(p=0,117)$.

Dalam peran interpersonal terdapat tiga peran pemimpin yang muncul secara langsung dari otoritas formal yang dimiliki pemimpin dan mencakup hubungan interpersonal dasar, yaitu peran sebagai yang di tuakan, peran sebagai penghubung dan peran sebagai pemimpin (leader). ${ }^{8}$

Seorang pemimpin bertanggung jawab atas hasil kerja orang dalam unit organisasi yang dipimpinnya. Dalam menjalankan peran interpersonal, seorang pemimpin harus memberi motivasi dan mendorong anak buahnya. ${ }^{8}$

Hasil wawancara dengan IPCLN di peroleh informasi bahwa perawat yang mampu melaksanakan pencegahan dan pengendalian infeksi dengan baik biasanya akan langsung di beri pujian, dinaikkan nilai SKP atau bahkan diikutsertakan dalam pelatihan sebagai penghargaan terhadap perawat tersebut, tetapi belum ada sanksi bagi petugas yang tidak PPIRS dengan baik.
Hasil observasi didapatkan bahwa kepala ruangan sebelum memulai kegiatan di ruangan ada memberikan arahan mengenai kegiatan yang akan di lakukan oleh perawat melalui pre confrence, tetapi hal ini tidak setiap hari dilakukan begitu juga dengan pengulangan informasi mengenai tujuan dan pentingnya melakukan PPIRS sesuai standar. Sebaiknya ini dilakukan setiap hari karena dorongan yang ada pada diri seseorang, mengarahkan pada tercapainya tujuan. Dorongan yang paling kuat menghasilkan adanya perilaku, baik yang berupa aktivitas terarah ke tujuan atau aktivitas tujuan. ${ }^{9}$

RSUP Dr.M.Djamil Padang sejak tahun 2013 telah mulai melakukan persiapan untuk penilaian akeditasi oleh tim KARS pusat dimana pada Tanggal 30 mei 2016 RSUP Dr.M.Djamil telah lulus akreditasi. Wawancara dan penyebaran kuesioner mulai dilaksanakan pada minggu pertama bulan Juni 2016 sehingga kemungkinan besar responden maupun informan masih segar ingatannya mengenai pelaksanaan PPIRS sesuai standar, dimana untuk persiapan akreditasi informasi mengenai PPIRS tentu saja telah banyak di berikan kepada petugas. Hal ini terlihat dari jumlah perawat yang telah mengikuti pelatihan PPIRS sebanyak (87,5\%).

Hasil uji Chi-square untuk peran informasional, diperoleh $p=0,003$. Hal ini menunjukkan ada hubungan antara peran informasional dengan pelaksanaan pencegahan dan pengendalian infeksi RS.

Dalam mengumpulkan informasi mengenai pelaksanaan PPIRS di ruang rawat inap bedah, IPCLN melakukan pemantauan terhadap kepatuhan petugas dalam melaksanakan tindakan keperawatan sesuai dengan prinsip PPIRS. Pemantauan tersebut tidak dikuti dengan pendokumentasian langsung pada lembar evaluasi kepatuhan petugas yang telah di sediakan oleh komite PPIRS. IPCLN melakukan pengisian blanko tersebut satu kali dalam seminggu berdasarkan pada ingatannya, sehingga ada peluang isi formulir tersebut bersifat subjektif.

Penilaian prestasi kerja yang rasional di terapkan secara objektif merupakan bagian yang penting baik bagi pegawai maupun bagi organisasi. Bagi para pegawai, penilaian tersebut berperan sebagai umpan balik bagi pengembangan karirnya. 
Bagi organisasi penilaian tersebut penting dalam pengambilan keputusan tentang berbagai hal seperti identifikasi kebutuhan program pendidikan dan pelatihan, rekrutmen, seleksi, program pengenalan, penempatan, promosi, sistem imbalan dan berbagai aspek lain. ${ }^{9}$

Hasil penelitian secara kuantitatif berdasarkan pengisian kuesioner oleh perawat pelaksana meski terdapat hubungan antara peran informasional dengan pelaksanaan PPIRS $(p=0,003)$, tetapi hanya $37,5 \%$ perawat yang merasakan peran informasional IPCLN baik, juga baik dalam melaksanakan PPIRS dan sebanyak $87,5 \%$ perawat yang merasakan peran informasional IPCLN tidak baik akan tetapi baik dalam melaksanakan PPIRS.

Hasil dari penelitian secara kuantitatif tersebut bertentangan dengan teori yang ada dimana berdasarkan teori di ketahui bahwa peranan seorang manajer sangat menentukan dari keberhasilan suatu organisasi untuk mencapai tujuan dari organisasi tersebut (Hariandja 2002 dalam Widhya et al, 2013). ${ }^{10}$ Peneliti kemudian mencari kebenaran dari hasil tersebut dengan melakukan observasi terhadap pelaksanaan pencegahan dan infeksi rumah sakit $d i$ ruang rawat inap bedah RSUP Dr.M.Djamil Padang.

Hasil observasi diketahui bahwa masih ada perawat yang tidak melakukan hand hygiene dan memakai hand scoen saat melakukan tindakan invasive, tidak segera melepas APD setelah melakukan tindakan keperawatan, masih ada spuit injeksi yang di buang dalam keadaan tertutup, masih ada safety box yang di isi melebihi kapasitas yang di perbolehkan (3/4), masih ada linen kotor yang di angkut tidak dengan menggunakan wadah khusus, masih ada limbah benda tajam pada tempat sampah infeksius. Hal ini menggambarkan bahwa pelaksanaan PPIRS di ruang rawat inap bedah belum optimal.

Perlu di sosialisasikan mengenai peran dan tanggung jawab IPCLN dalam pengendalian infeksi rumah sakit. Hal ini sebaiknya perlu juga di dukung dengan pemberian reward dan punishment bagi IPCLN yang menjalankan upaya tersebut.
Hasil penelitian Mustariningrum et al (2015) menunjukkan dengan adanya supervisi dari atasan (IPCN dan Komite PPI) mampu meningkatkan pengetahuan dan keterampilan IPCLN dalam menjalankan tugasnya. ${ }^{11}$ Supervisi dari atasan harus dilakukan secara objektiv yang bertujuan untuk pembinaan kinerja IPCLN dalam memantau perawat pelaksana dan menilai secara objektiv pelaksanaan PPIRS yang di lakukan oleh perawat pelaksana.

Dalam menjalankan peran decisional, IPCLN memiliki kewenangan dalam menegur jika ada personil di unit rawat nya yang tidak patuh dalam melaksanakan pencegahan dan pengendalian infeksi rumah sakit, melakukan evaluasi kepatuhan petugas, menempatkan sarana, prasarana dan tenaga yang di butuhkan serta menyelesaikan setiap permasalahan yang terkait dengan pelaksanaan pencegahan dan pengendalian infeksi rumah sakit.

Hasil analisis secara statistik hubungan antara peran decisional IPCLN dengan pelaksanaan PPIRS menunjukkan ada hubungan antara peran decisional IPCLN dengan pelaksanaan pencegahan dan pengendalian infeksi RS ( $p=0,000)$.

Hasil yang sama juga didapatkan dari hasil penelitian Marliany et al (2015), dimana terdapat hubungan bermakna antara peran decisional kepala ruangan dengan sikap etis perawat pelaksana terhadap klien $(p=0,002) .{ }^{7}$

Hasil penelitian secara kuantitatif berdasarkan pengisian kuesioner oleh perawat pelaksana meski terdapat hubungan antara peran decisional dengan pelaksanaan PPIRS ( $p$-value $=0,000)$ akan tetapi hanya $34,4 \%$ perawat yang merasakan peran decisional IPCLN baik, juga baik dalam melaksanakan PPIRS dan sebanyak 93,8\% perawat yang merasakan peran decisional IPCLN tidak baik akan tetapi baik dalam melaksanakan PPIRS.

Peran kewirausahaan IPCLN sebagai bagian dari peran decisional menuntut manajer agar mampu dan selalu berusaha memperbaiki kinerja unitnya dan beradaptasi dengan perubahan lingkungan, mencari serta menerapkan ide baru untuk organisasinya. 
Hasil wawancara diketahui bahwa IPCLN melakukan evaluasi terhadap perawat ruangan berdasarkan pada blanko atau daftar tilik yang telah di sediakan oleh komite PPIRS. Blanko atau daftar tilik tersebut diisi oleh IPCLN setiap minggunya berdasarkan ingatan dari pengamatannya selama seminggu sebelumnya, sehingga penilaian yang di lakukan oleh IPCLN tidak objektif dan sering berbeda dengan penilaian yang di lakukan oleh IPCN. Hasil penilaian yang tidak objektif tentu saja tidak dapat mewakili dalam mengevaluasi kinerja perawat sehingga kinerja unit dalam melaksanakan pencegahan dan pengendalian infeksi RS juga sulit diperbaiki.

Semua IPCLN yang telah dipilih oleh manajemen tentunya telah memenuhi kriteria sebagai seorang pemimpin yang mampu mempengaruhi perilaku staf untuk mencapai tujuan organisasi dalam hal ini melaksanakan pencegahan dan pengendalian infeksi dengan baik. IPCLN sebagai seorang terpilih seharusnya memiliki motivasi yang tinggi dalam mencapai pelaksanaan PPIRS yang baik salah satunya dengan selalu mengawasi, menilai dan mengevaluasi kinerja staf.

Peran decisional IPCLN sebagai resource allocator diketahui dari pengamatan terhadap sarana, prasarana, yang mendukung pelaksanaan pencegahan dan pengendalian infeksi rumah sakit. Peneliti menemukan masih terdapat kekurangan seperti habisnya kantong plastik kuning untuk laken infeksius, safety box, kertas tisu pada bak wastafel. IPCLN telah melaporkan hal tersebut pada bagian logistik namun stok barang tersebut masih kosong.

Pihak manajemen harus menjadikan hal ini sebagai prioritas dan lebih memperhatikan kepada kebutuhan dari pegawainya. Elton Mayo (1930) dalam Nursalam (2011) menekankan bahwa jika manajemen memberikan perhatian penuh kepada pegawai, maka hasil produksi akan meningkat dengan tidak mengabaikan kondisi lingkungan kerja. Teori tersebut dikenal dengan hawthorne effect, dimana seseorang akan merespons kejadian dan terus belajar manakala mereka merasa terus di perhatikan dan di dukung oleh manajemen. ${ }^{5}$
Hasil penelitian kualitatif menunjukkan bahwa peran decisional IPCLN belum optimal dan jika di bandingkan dengan hasil pengamatan terhadap pelaksanaan pencegahan dan pengendalian infeksi rumah sakit yang juga masih belum optimal, ini menggugurkan hasil dari penelitian kuantitatif dimana secara kuantitatif menunjukkan sebanyak 93,8\% perawat yang merasakan peran decisional IPCLN tidak baik akan baik dalam melaksanakan PPIRS.

\section{Hubungan Variabel Confounding dengan Pelaksanaan PPIRS}

Hasil uji statistik dari penelitian ini didapatkan nilai $p=0,648$, berarti tidak ada perbedaan yang signifikan rerata umur responden yang melaksanakan pencegahan dan pengendalian infeksi RS baik dengan kurang baik.

Sopiah (2008) dalam Setiowati (2010) menyatakan bahwa umur akan mempengaruhi individu dalam bekerja. Usia semakin bertambah, maka semakin sedikit kesempatan alternative pekerjaan bagi mereka. Pekerja yang usianya makin tua, kecil kemungkinan akan berhenti karena dengan masa kerja mereka yang lebih panjang akan mendapatkan gaji yang lebih tinggi, tunjangan yang lebih beragam. ${ }^{12}$

Tidak ada hubungan antara umur dengan pelaksanaan pencegahan dan pengendalian infeksi rumah sakit kemungkinan di karenakan ada faktor lain yang berkontribusi terhadap keinginan perawat dalam melaksanakan pencegahan dan pengendalian infeksi rumah sakit dengan baik.

Jenis kelamin membedakan cara berfikir dan bertindak seseorang. Kodratnya perempuan lebih sering tidak masuk kerja dibandingkan laki-laki misalnya karena hamil atau melahirkan, tetapi karyawan wanita cenderung lebih rajin, disiplin, dan sabar. $^{13}$

Hasil uji Chi-square untuk hubungan jenis kelamin dengan pelaksanaan PPIRS, diperoleh $p$ value $=1,000$. Hal ini menunjukkan tidak ada hubungan antara jenis kelamin dengan pelaksanaan pencegahan dan pengendalian infeksi RS. 
Hal ini sejalan dengan hasil peneltian Aswat (2010) dalam Adam (2014), yang menunjukkan bahwa jenis kelamin tidak memiliki hubungan yang signifikan dengan motivasi kerja $(O R=1,083$; $P>0,05) .^{14}$

Pendidikan merupakan indikator yang menunjukkan kemampuan individu dalam menyelesaikan pekerjaan yang menjadi tanggung jawabnya. $^{15}$

Penelitian menunjukkan bahwa terdapat suatu hubungan positif antara taraf pendidikan dengan kinerja. Hasil penelitian Adji (2002) dalam Adam (2014) menunjukkan bahwa tingkat pendidikan merupakan faktor yang mempunyai hubungan paling dominan dengan kinerja perawat $(\mathrm{OR}=80.325, p<$ $0,05)$ dimana perawat yang berpendidikan SPK + D1 Kebidanan berpeluang mempunyai kinerja kurang baik 80,3 kali dibandingkan perawat yang berpendidikan D III Keperawatan. ${ }^{14}$

Hasil uji Chi-square pada penelitian ini diperoleh $p=0,102$ dibandingkan dengan nilai koefisien $\geq 0,05$, maka $p>0,05$. Hal ini menunjukkan tidak ada hubungan antara pendidikan dengan pelaksanaan pencegahan dan pengendalian infeksi RS.

Tidak adanya hubungan antara pendidikan dengan pelaksanaan pencegahan dan pengendalian infeksi rumah sakit ini kemungkinan di sebakan oleh karena distribusi responden yang homogen dimana sebagian besar responden $(85,4 \%)$ dengan tingkat pendidikan D3 dan hanya 1 orang (2,1\%) yang berpendidikan $\mathrm{S} 2$.

Faktor lama kerja dikaitkan dengan hubungan senioritas atau anggapan bahwa semakin lama seseorang bekerja semakin lebih berpengalaman dan berpengaruh terhadap produktivitas kerja. ${ }^{15}$

Hasil uji statistik didapatkan nilai $p=0,256$ berarti tidak ada perbedaan yang signifikan rerata lama bekerja responden yang melaksanakan pencegahan dan pengendalian infeksi RS baik dengan kurang baik.

Masa kerja biasanya dikaitkan dengan waktu mulai bekerja, dimana pengalaman kerja juga ikut menentukan kinerja seseorang. Semakin lama masa kerja maka kecakapan akan lebih baik karena sudah menyesuaikan diri dengan pekerjaanya. Akan tetapi kejenuhan terhadap pekerjaan juga terkadang timbul akibat masa kerja yang terlalu lama. Hal ini kemungkinan merupakan penyebab tidak adanya hubungan antara lama bekerja dengan pelaksanaan pencegahan dan pengendalian infeksi rumah sakit, dimana dari hasil analisis untuk karakeristik lama bekerja responden didapatkan rerata lama bekerja responden adalah 12,04 tahun dengan lama bekerja tertinggi 36 tahun.

Hasil uji Chi-square untuk hubungan pelatihan dengan pelaksanaan PPIRS diperoleh $p=0,674$ dibandingkan dengan nilai koefisien $\geq 0,05$, maka $p>$ 0,05 . Hal ini menunjukkan tidak ada hubungan yang signifikan antara pelatihan dengan pelaksanaan pencegahan dan pengendalian infeksi RS.

Pada kuesioner tidak di rinci mengenai tingkat pelatihan PPIRS yang ikuti oleh perawat apakah tingkat dasar atau lanjutan dan telah berapa kali responden mengikuti pelatihan sehingga kemungkinan hal ini menjadi penyebab tidak ada hubungan antara pelatihan dengan pelaksanaan pencegahan dan pengendalian infeksi rumah sakit

\section{SIMPULAN}

Peran manajer IPCLN dan pelaksanaan PPIRS masih belum optimal di ruang rawat inap bedah RSUP Dr.M.Djamil Padang Tahun 2016.

Variabel confounding tidak dapat di ketahui dari penelitian ini di karenakan analisa multivariat tidak dapat di lakukan dan tidak satupun dari variabel confounding yang menunjukkan hubungan bermakna terhadap pelaksanaan PPIRS.

\section{SARAN}

Bagi pihak manajemen agar dapat menerbitkan SPO yang mengatur mengenai peran IPCLN di ruang rawat inap,

Kinerja IPCLN perlu di evaluasi secara rutin dan di lakukan supervisi secara objektiv tanpa pemberitahuan sebelumnya oleh IPCN

Perlu di pertimbangkan pemberian reward bagi pegawai yang berprestasi atau sanksi bagi pegawai yang tidak bekerja dengan baik 
Penyediaan sarana dan prasana pelu menjadi perhatian bagi pihak manajemen agar pencegahan dan pengendalian infeksi RS dapat optimal.

\section{UCAPAN TERIMA KASIH}

Terima kasih kepada Direktur, Ka.Instalasi Bedah RSUP RSUP Dr.M.Djamil Padang yang telah memberi izin untuk melakukan penelitian serta Komite PPIRS dan IPCLN yang telah banyak berperan dalam penelitian ini.

\section{DAFTAR PUSTAKA}

1. Darmadi. Infeksi nosokomial: problematika dan pengendaliannya. Jakarta: Salemba Medika; 2008.

2. Departemen Kesehatan RI. Pedoman manajerial pencegahan dan pengendalian infeksi rumah sakit dan pelayanan kesehatan lainnya. Jakarta: Departemen Kesehatan RI; 2008.

3. Simamora RH. Buku ajar manajemen keperawatan. Jakarta: EGC; 2012.

4. Handiyani $\mathrm{H}$, Allenidekania, Eryando $\mathrm{T}$. Hubungan peran dan fungsi manajemen kepala ruangan dengan keberhasilan pelaksanaan program pengendalian infeksi nosokomial. Jurnal Keperawatan Indonesia. 2004;8:54-61.

5. Nursalam. Manajemen keperawatan, apikasi dalam praktik keperawatan profesional. Edisi ke3. Jakafta: Salemba Medika; 2011.

6. Jayatri AM, Samian. Hubungan antara peranan manajer dengan kepuasan kerja pada karyawan PT Perkebunan Nusantara $X$ (PERSEREO) di PG Toelangan Sidoarjo. Insan. 2010;12:53-65.

7. Marliany $H$, Nurachmah $E$, Handiyani $H$. Hubungan peran kepala ruang dengan sikap etis perawat pelaksana terhadap klien yang dipersepsikan oleh perawat pelaksana di RSUD Kota Tasikmalaya (tesis). Depok: Fakultas IImu Keperawatan Universitas Indonesia; 2010.

8. Thoha M. Kepemimpinan dalam manajemen. Jakarta: CV.Rajawali; 2015.

9. Fathoni A. Organisasi \& manajemen sumber daya manusia. Jakarta: PT Rineka Cipta; 2006.

10. Widhya C, Rahardjo K, Djudi M. Pengaruh peran manajer terhadap motivasi kerja karyawan. [serial online] 2013 (diunduh 21 Desember 2015). Tersedia dari: http://download.portalgaruda.org.

11. Mustariningrum DLT, Koeswo M, Ahsan. Kinerja IPCLN dalam pencegahan dan pengendalian infeksi di rumah sakit: peran pelatihan, motivasi kerja dan supervisi. Jurnal Aplikasi Manajemen (JAM). 2015;13:643-52.

12. Setiowati D. Hubungan kepemimpinan efektif head nurse dengan penerapan budaya keselamatan pasien oleh perawat pelaksana di RSUPN Dr. Cipto Mangunkusumo Jakarta (tesis). Depok: Fakultas IImu Keperawatan Universitas Indonesia; 2010.

13. Nivalinda D, Hartini I, Santoso A. Pengaruh motivasi perawat dan gaya kepemimpinan kepala ruang terhadap penerapan budaya keselamatan pasien oleh perawat pelaksana pada rumah sakit pemerintah di Semarang. Jurnal Managemen Keperawatan. 2013;1:138-45.

14. Adam. Hubungan supervisi kepala ruangan dengan kinerja perawat pelaksana rawat inap dalam pendokumentasian asuhan keperawatan di RSUD Haji Propinsi Sulawesi Selatan (tesis). Makassar: Fakultas Kedokteran Universitas Hasanuddin; 2014.

15. Hasibuan MSP. Organisasi \& motivasi, dasar peningkatan produktivitas. Jakarta: PT Bumi Aksara; 2007. 